\title{
The Relationship between Asthma and Obesity in Urban Early Adolescents
}

\author{
Melanie Jay, M.D., M.S., ${ }^{1}$ N. Ari Wijetunga, M.S., ${ }^{2}$ Cesalie Stepney, Ed.M.,, ${ }^{3}$ Karen Dorsey, M.D., Ph.D., \\ Danica Marie Chua, B.A., ${ }^{5}$ and Jean-Marie Bruzzese, Ph.D. ${ }^{5}$
}

Asthma and obesity, which have reached epidemic proportions, impact urban youth to a great extent. Findings are inconsistent regarding their relationship; no studies have considered asthma management. We explored the association of obesity and asthma-related morbidity, asthma-related health care utilization, and asthma management in urban adolescents with uncontrolled asthma. We classified 373 early adolescents (mean age $=12.8$ years; $82 \%$ Hispanic or Black) from New York City public middle schools into 4 weight categories: normal (body mass index $[\mathrm{BMI}]<85$ th percentile); overweight (85th percentile $\leq \mathrm{BMI}<95$ th percentile); obese (95th percentile $\leq \mathrm{BMI}<97$ th percentile); and very obese (BMI $\geq 97$ th percentile). We compared sample obesity prevalence to national estimates, and tested whether weight categories predicted caregiver reported asthma outcomes, adjusting for age and race/ethnicity. Obesity prevalence was $37 \%$, with $28 \%$ of the sample being very obese; both rates were significantly higher than national estimates. We found no significant differences in asthma-related health care utilization or asthma management between weight categories, and a few differences in asthmarelated morbidity. Relative to normal weight and obese youth, overweight youth had higher odds of never having any days with asthma-related activity limitations. They also had higher odds of never having asthmarelated school absences compared with obese youth. Overweight youth with asthma-related activity limitations had more days with limitations compared with normal weight youth. Overweight, but not obese youth, missed more school due to asthma than normal weight youth. Overweight and obesity prevalence was very high in urban, Hispanic, and Black adolescents with uncontrolled asthma, but not strongly associated with asthmarelated morbidity, asthma-related health care utilization, or asthma management practices.

\section{Introduction}

A STHMA AND OBESITY in American youth are significant public health concerns, as both diseases have a high prevalence and have significantly increased over time. ${ }^{1,2}$ Thirteen percent of all children in the United States have been diagnosed with asthma, ${ }^{3}$ and asthma prevalence, morbidity, and mortality are relatively high among adolescents, ${ }^{2,4-6}$ as well as urban youth. ${ }^{7,8}$ According to the National Health and Nutrition Examination Survey (NHANES), the number of U.S. born youth aged 12-19 with obesity increased from 1 in 20 in the late $1970 \mathrm{~s}^{9}$ to almost 1 in 6 in $2008 .{ }^{10}$ While obesity is generally lower in urban communi- ties, $^{11}$ it is higher among children of a lower socioeconomic status, regardless of geographic location. ${ }^{12,13}$ In addition, both asthma and obesity disproportionally affect ethnic minority populations. $2,7,10,14$

Studies conducted on children and adolescents consistently link asthma and obesity. ${ }^{15}$ Hispanics and Blacks, ${ }^{16,17}$ as well as individuals from households of a lower socioeconomic status, ${ }^{18}$ are more likely to be both obese and diagnosed with asthma. Gender complicates this relationship with the association being stronger in girls than boys, ${ }^{19,20}$ with early puberty potentially accounting for this relationship. ${ }^{15}$

While early studies suggested that reduced activity due to asthma may lead to obesity, most prospective studies have

This study was performed primarily at the New York University School of Medicine in collaboration with investigators at the Columbia University College of Physicians and Surgeons. This was a school-based study, and the schools were drawn from public schools that comprise the NYC Department of Education.

Clinical Trial Registry Information: Family Approach to Managing Asthma in Early Teens; NCT00241852.

${ }^{1}$ Division of General Internal Medicine, New York University School of Medicine, New York, New York.

${ }^{2}$ Albert Einstein College of Medicine, Yeshiva University, Bronx, New York.

${ }^{3}$ Department of Psychology, Rutgers University, New Brunswick, New Jersey.

${ }^{4}$ Department of Pediatrics, School of Medicine, Yale University, New Haven, Connecticut.

${ }^{5}$ Department of Child and Adolescent Psychiatry, New York University School of Medicine, New York, New York. 
shown that overweight or obesity precedes asthma. ${ }^{15,21,22}$ This is further supported by the fact that weight loss studies have shown that obese patients with asthma who lose weight also show significant improvements in asthma morbidity. ${ }^{22,23}$ The relationship between obesity and asthma-related outcomes is less clear, with some studies, ${ }^{24-28}$ but not others, ${ }^{29-31}$ suggesting that obese children with asthma have worse asthma outcomes.

Several mechanisms have been proposed as to why obesity may worsen asthma. ${ }^{32}$ Increased abdominal mass may reduce lung volumes and functional residual capacity, 33 leading to shortened airway diameter. ${ }^{32,34}$ Obese patients breathe at higher frequencies and lower tidal volumes, which may increase airway hyper-responsiveness. ${ }^{32,35}$ In addition, obesity causes chronic low-grade inflammation with elevations in cytokines, chemokines, and cytokine receptors that may increase smooth muscle contractility, and, thus, increase airway hyper-responsiveness. ${ }^{23,32}$ Thus, we would expect obese youth to have increased asthma morbidity and healthcare utilization for asthma.

An important determinant of asthma control involves how well the disease is managed by patients (eg, avoiding allergens, making routine doctor visits, and symptom monitoring). Understanding the relationship between asthma management and obesity has the potential to clarify whether the association between these 2 diseases is due to physiologic differences or differences in health behaviors and asthma management practices between obese and non-obese children. This has important clinical implications, because shedding light on specific asthma management behaviors that are more challenging for obese youth will help identify targets for intervention. Despite the significance of this, to date the relationship between asthma management and obesity has not been studied.

In this study, we aimed at describing the prevalence of overweight and obesity in a sample of inner city, predominately Hispanic, and Black early adolescents with uncontrolled asthma, comparing the sample prevalence with national estimates. We also sought to characterize the relationship between obesity, asthma-related morbidity, and urgent health care utilization for asthma in this at-risk population. We hypothesized that our sample would have a higher prevalence of obesity than national estimates, and that asthma morbidity and urgent health care utilzation would be associated with obesity. In addition, we explored whether asthma mangement practices were associated with obesity.

\section{Materials and Methods}

\section{Participants}

We conducted a secondary data analysis of baseline data from a controlled trial testing the efficacy of a family-focused, school-based intervention to improve asthma control among inner-city, Hispanic, and Black early adolescents. ${ }^{36}$ Study procedures were approved by the institutional review boards of the New York University School of Medicine, Columbia University College of Physicians and Surgeons, New York City Department of Education, and New York City Department of Health and Mental Hygiene.

Families were drawn from 27 participating middle schools in 3 of the 5 boroughs of New York City (Manhattan,
Bronx, and Brooklyn); eligible schools had a high proportion of Hispanic and Black or African-American students, and students who were eligible for free or reduced lunch. Enrollment took place over 4 years (2005-2008) with 5-9 schools participating each year; each year, we enrolled new schools, with the exception of 1 school, in which we enrolled 2 cohorts in 2 different school years.

Students eligible for the controlled trial were sixth through eighth graders whose caregivers reported that their child had a previous diagnosis of asthma, had taken prescribed asthma medication the previous year, and had uncontrolled asthma. Building on National Heart, Lung and Blood Institute (NHLBI) criteria $^{37}$ in place at the study's onset, uncontrolled asthma was defined as (1) daytime symptoms every day, or night awakening 3 or more times a week, (2) daytime symptoms 3-6 days a week, or night awakening 3 or more times per month, plus at least 1 urgent visit for asthma to a doctor, hospital, or Emergency Department (ED) in the past 12 months, or (3) intermittent symptoms, and at least 2 visits for urgent care. These criteria are consistent with subsequent NHLBI criteria for uncontrolled asthma. ${ }^{38}$

Three hundred ninety-two families enrolled in the controlled trial. Of these, 379 students had baseline staffmeasured height and weight measurements. We excluded 6 underweight students (body mass index $[\mathrm{BMI}]<5$ th percentile) from the present analyses, as they were too small of a comparison group, resulting in a sample size of 373 for this study.

\section{Measurements}

Caregivers and students completed baseline surveys after school or on the weekends at the schools. Trained research assistants administered the surveys, which took approximately 30-45 minutes to complete.

Demographic characteristics. Caregivers reported on how they were related to the child, their education level, employment status, primary language spoken, and whether they were born in the United States. Child demographics included gender, age, and race/ethnicity.

Anthropometric measurement. We calculated BMI from staff-measured height (to the nearest half inch) and weight (to the nearest half pound) measurements using the formula: (weight in pounds / [height in inches] $\left.]^{2}\right) \times 703$. BMI percentiles were standardized by age and gender using formulas from Center for Disease Control (CDC). ${ }^{39}$ When an analog scale and stadiometer were available at the school, staff used the school's devices. Otherwise, staff used Homedics ${ }^{\circledR} 315$ digital scales and a measuring tape affixed to a wall. We calibrated the digital scales against a single analog scale. Staff instructed the students to remove heavy articles of clothing and their shoes before taking the measurements.

Using BMI percentiles, we classified children into 4 weight categories based on federal guidelines: underweight (BMI $<5$ th percentile); normal ( 5 th $\leq \mathrm{BMI}<85$ th percentile); overweight $(85 \mathrm{th} \leq \mathrm{BMI}<95$ th percentile); and obese $(\mathrm{BMI} \geq$ 95th percentile). Since our sample was particularly heavy, we followed the criteria reported by Ogden et al. in their recent analysis of NHANES data, and further divided the obese group into those with a BMI greater than the 97th percentile (herein referred to as "very obese"). ${ }^{10}$ We constructed 3 weight category schemas to compare weight categories: (1) normal weight versus overweight (85th percentile $\leq \mathrm{BMI}<95$ th percentile) 
versus obese (BMI $\geq 95$ th percentile); (2) normal weight versus overweight/obese (BMI $\geq 85$ th percentile); and (3) normal weight versus overweight/obese (85th percentile $\leq$ BMI $<97$ th percentile) versus very obese (BMI $\geq 97^{\text {th }}$ percentile).

Asthma morbidity. Caregivers reported on the number of days in the last 2 weeks their child experienced (1) daytime symptoms (ie, wheeze, shortness of breath, coughing, and chest tightness), (2) night awakening due to asthma, (3) asthma-related school absences, and (4) days with activity limitation due to asthma. They also completed a modified version of the 4-item Asthma Symptom Scale, ${ }^{40}$ where they rated the severity of symptoms on a 4-point likert scale $(0=$ none, $3=$ severe-distressing $)$. We computed an average symptom severity score (Cronbach's $\alpha$ for this sample $=0.77$ ).

Urgent health care utilization. To assess urgent health care utilization over the previous 2 months, caregivers reported the number of asthma-related acute medical visits to a doctor or clinic, ED visits, and hospitalizations to a doctor or clinic.

Asthma management. Caregivers reported on 3 aspects of the child's asthma management: prevention behaviors, management of symptoms, and use of long-term control medication. Caregivers completed the Asthma Prevention Index, ${ }^{41}$ which consists of 9 items regarding steps the child takes to prevent asthma symptoms scored on a 3-point scale $(0=$ no, $1=$ yes, but not on a regular basis, and $2=y e s$, on a regular basis; Cronbach's $\alpha$ for this sample $=0.72$ ). To compute the total number of prevention steps taken, we dichotomized this variable to yes/no, and summed the items. To assess what students do to manage exacerbations, caregivers completed the Asthma Management Index, ${ }^{41}$ where they indicated whether or not their child took each of 7 steps to manage symptoms once they began (Cronbach's $\alpha$ for this sample $=0.53$ ). We summed the items to compute the total number of management steps taken. Caregivers also provided a list of the medications their child was currently taking. From this list, we coded whether the student was taking a long-term control medication or not.

\section{Data analysis}

Demographics and weight status. We tested the relationship between demographic correlates and weight status using linear regression when data were continuous, and chi-square testing when data was categorical.

Comparison of obesity prevalence to population estimates. Since we collected baseline data from 2005 to 2008, to compare our sample with population estimates of weight status, we used NHANES data collected from 2003 to $2006^{42}$ and 2007 to 2008. ${ }^{10}$ These datasets included children aged 6 through 19 years old, and were subdivided by age (6-11 and 12-19) and race (Non-Hispanic Black, Mexican American, and Hispanic [2007-2008 only]). We used chi-square goodness-of-fit tests to compare prevalence of overweight and obese students in the current sample with NHANES population estimates. For race specific comparisons, only the Hispanic and Black students in our sample were considered. Since we did not ask about specific ethnic identity among the Hispanics, we compared those who reported being Hispanic in our sample with the Mexican American group in the 2003-2006 NHANES dataset, and with both the Mexican American and Hispanic groups for the 2007-2008 dataset.

Asthma morbidity, healthcare utilization, and asthma management. To explore the relationship between obesity and asthma morbidity, asthma-related urgent health care utilization, and asthma management, we constructed regression models using linear, logistic, and Poisson regression for continuous, binary, and count outcomes, respectively. For count outcomes with more reported zeros than expected from a Poisson distributed variable, we used zero-inflated Poisson regression (ZIP); these variables included nights woken, days with activity limitation and school absences for asthma morbidity, and ED visits and acute visits for urgent health care utilization. The ZIP model assumes that the study sample is from 2 subpopulations: a "sure zero population" (eg, those who would not have school absences) and a "nonsure zero population" (eg, those who would have school absences). ${ }^{43,44}$ The ZIP distribution simultaneously models the probability of belonging to the "sure zero population," and the mean number of events for the "non-sure zero population." To interpret the ZIP results, we provide the odds ratios for the "sure zero population," and the rate ratios (RR) for the "non-sure zero population" along with 95\% confidence intervals (CI) for the estimates.

For each outcome, we fit 2 models. First, we fit unadjusted models where weight category was entered as the sole predictor of asthma morbidity, health care utilization, and management. Next, to verify that significant effects in the unadjusted models were not due to demographic differences, we controlled for the demographic factors that were significantly associated with weight; these adjusted models were run only for the significant unadjusted models. We performed analyses using the statistics software R version 2.11.1 (R Development Core Team, Vienna, Austria). We judged statistical significance at level $\alpha=0.05$, and only interpreted effects for models attaining overall significance. Given that there were a few differences when looking at the 3 different weight classification schema, we decided to report our main analyses using the first weight classification schema: normal weight versus overweight (85th percentile $\leq \mathrm{BMI}<95$ th percentile) versus obese (BMI $\geq 95$ th percentile). We also report significant differences found in models using schema 2 and 3 that are inconsistent with those using schema 1.

\section{Results}

\section{Participant characteristics}

Table 1 shows the distribution of child and family characteristics, baseline asthma characteristics, and BMI weight classification. The mean age of the sample was 12.8 years (standard deviation $=1.1) ; 54 \%$ were men. The majority of children $(99 \%)$ had persistent asthma, yet only $68 \%$ of the parents reported that their child was taking a long-term control medication. Since less than $7 \%$ of the sample reported asthma-related hospitalizations in the previous 2 months, we were unable to construct a valid model predicting hospitalizations with weight status. Most students $(56 \%, 209 / 373)$ were either overweight or obese. Among the obese students, the vast majority (76\%, 105/139) were very obese as defined by a gender and age-adjusted BMI percentile of 97 or higher. Among demographic predictors, only child age $\left(F_{(2,370)}=3.14, P=0.045\right)$ and race/ethnicity $\left(\chi^{2}{ }_{(4)}=10.279, \quad P=0.036\right)$ were significantly associated with weight status. Higher adolescent age was associated with lower BMI percentile $(\beta=-2.725, P=0.0218)$, and analysis of race/ ethnicity indicates that Hispanic adolescents have significantly greater BMI percentiles than Non-Hispanic Blacks $(\beta=7.717$, 
Table 1. Family and Asthma Characteristics and Body Mass Index Weight Classification At BASELINe $(N=373)$

\begin{tabular}{|c|c|}
\hline & $\%(n)$ \\
\hline \multicolumn{2}{|l|}{ Child characteristics } \\
\hline Age, mean $\pm S D$, years & $12.8 \pm 1.1$ \\
\hline Male & $54.4(203)$ \\
\hline \multicolumn{2}{|l|}{ Race/ethnicity } \\
\hline Hispanic & $48.3(180)$ \\
\hline Black, not of Hispanic origin & $33.8(126)$ \\
\hline Two or more races & $8.8(33)$ \\
\hline Other & $9.1(34)$ \\
\hline \multicolumn{2}{|l|}{ Caregiver characteristics } \\
\hline \multicolumn{2}{|l|}{ Relation to child } \\
\hline Biological or adoptive mother & $89.5(334)$ \\
\hline Other & $10.5(39)$ \\
\hline \multicolumn{2}{|l|}{ Highest level of education complete } \\
\hline Less than high school & $33.6(125)$ \\
\hline High school, GED, or vocational school & $24.2(90)$ \\
\hline Partial college & $30.1(112)$ \\
\hline College graduate & $12.1(45)$ \\
\hline \multicolumn{2}{|l|}{ Employment status } \\
\hline Unemployed & $51.6(192)$ \\
\hline Employed, part time & $11.3(42)$ \\
\hline Employed, full time & $37.1(138)$ \\
\hline \multicolumn{2}{|l|}{ Primary language } \\
\hline English & $81.0(302)$ \\
\hline Spanish & $19.0(71)$ \\
\hline Born in the United States & $58.7(219)$ \\
\hline \multicolumn{2}{|l|}{ Baseline asthma characteristics } \\
\hline \multicolumn{2}{|l|}{ NHLBI Classification } \\
\hline Intermittent & $1.3(5)$ \\
\hline Mild persistent & $33.3(124)$ \\
\hline Moderate persistent & $31.6(118)$ \\
\hline Severe persistent & $33.8(126)$ \\
\hline \multicolumn{2}{|l|}{ In past 2 months had at least one } \\
\hline Urgent visit to a doctor for asthma & $47.2(176)$ \\
\hline ED visit for asthma & $22.8(85)$ \\
\hline Hospitalization for asthma & $6.7(25)$ \\
\hline Taking a long-term control medication & $67.8(253)$ \\
\hline \multicolumn{2}{|l|}{ BMI weight classification } \\
\hline $\begin{array}{l}\text { Normal ( } \geq 5 \text { th percentile, but }<85 \text { th } \\
\text { percentile) }\end{array}$ & $44.0(164)$ \\
\hline $\begin{array}{l}\text { Overweight }(\geq 85 \text { th percentile, but } \\
<95 \text { th percentile })\end{array}$ & $18.8(70)$ \\
\hline $\begin{array}{l}\text { Obese }(\geq 95 \text { th percentile, but }<97 \text { th } \\
\text { percentile) }\end{array}$ & $9.1(34)$ \\
\hline Very obese ( $\geq 97$ th percentile) & $28.1(105)$ \\
\hline
\end{tabular}

$\mathrm{SD}$, standard deviation; GED, general equivalency diploma; NHLBI, National Heart, Lung and Blood Institute; ED, Emergency Department; BMI, body mass index.

$P=0.022)$ on an average. There were no differences in NHLBI classification by weight classification.

\section{Comparison of obesity prevalence to population estimates}

Chi-square goodness-of-fit tests comparing the proportion of overweight (BMI $\geq 85$ th percentile), obese (BMI $\geq 95$ th percentile), and very obese (BMI $\geq 97$ th percentile), in our sample $(56.0 \%, 37.3 \%$, and $28.4 \%$, respectively), with population estimates in each of these categories revealed that overall our sample was significantly heavier than all
NHANES comparisons ( $P<0.001$ for all comparisons). When race/ethnicity is considered, the proportion of overweight, obese, and very obese $(62.8 \%, 43.9 \%$, and $33.3 \%$, respectively) Hispanic children in our sample was significantly higher than all relevant NHANES comparisons $(P<0.001$ for all comparisons), with proportions in each category for our sample roughly twice the national estimates. In contrast, among NonHispanic Blacks, the proportion of overweight $(49.2 \%)$, obese $(27.8 \%)$, and very obese $(49.2 \%, 27.8 \%$, and $22.2 \%$, respectively) in our sample was similar to the NHANES estimates.

\section{The relationship of obesity to asthma morbidity, health care utilization, and asthma management practices}

Table 2 presents the distribution of each outcome by weight category. Table 3 reports the results of the ZIP models predicting asthma morbidity and urgent health care utilization with weight status as defined by the first weight category schema (eg, normal versus overweight versus obese).

Asthma morbidity. Weight status was a statistically significant predictor of caregiver-reported activity limitations and school absences due to asthma. Regarding days with activity limitations, overweight youth had significantly higher odds of being in the "sure zero population" compared with normal weight and obese youth-that is, they had higher odds of being in the population who would not have asthmarelated activity limitations. For school absences due to asthma, overweight youth had significantly higher odds of being in the "sure zero population" (ie, the population who would not have school absences) compared with obese youth. In the "non-sure zero population"-in those who would likely have school absences or activity limitations-overweight youth had significantly more school absences and days with activity limitations than normal weight youth. These effects remained significant after adjusting for child age and ethnicity. Modeling indicated that the normally and Poisson distributed variables (ie, Asthma Symptom Severity Scale mean score and number of symptom days) were not significantly associated with weight status.

Urgent health care utilization. Weight status was not associated with asthma-related acute medical visits to a doctor or clinic or ED visits.

Asthma management. Weight status was not associated with the total number of prevention or management steps. In addition, weight status was not associated with taking longterm control asthma medication.

Analyses with weight category schema 2 and schema 3. Results were consistent when using the second and third weight category schemas with one exception: the second weight category schema (normal weight versus overweight/obese) predicting asthma-related ED visits in the "non-sure zero group" (ie, those who would have ED visits) was statistically significant $(P=0.043)$. Overweight/obese children had significantly more ED visits than normal weight children $(\mathrm{RR}=1.59,95 \% \mathrm{CI}=1.05-2.40, P=0.029)$.

\section{Discussion}

Our study did not show a strong link between obesity and asthma. Caregivers of obese children did not report worse asthma morbidity (ie, number of nights awoken, days with symptoms, or rating of symptom severity), greater 
Table 2. Distribution of Outcomes by Weight Category

\begin{tabular}{|c|c|c|c|}
\hline & Normal & OW & $O B$ \\
\hline & \multicolumn{3}{|c|}{ Asthma morbidity $(\%[n])$} \\
\hline \multicolumn{4}{|l|}{ Days with symptoms in previous 2 weeks } \\
\hline 0 & $10.4(17)$ & $11.4(8)$ & $6.5(9)$ \\
\hline $1-2$ & $19.0(31)$ & $27.1(19)$ & $14.4(20)$ \\
\hline $3-4$ & $25.1(41)$ & $25.8(18)$ & $33.8(47)$ \\
\hline $5-6$ & $17.8(29)$ & $14.3(10)$ & $24.4(20)$ \\
\hline 7 or more & $27.7(45)$ & $21.4(15)$ & $20.9(43)$ \\
\hline \multicolumn{4}{|l|}{ Nights woken in previous 2 weeks } \\
\hline 0 & $35.2(57)$ & $37.1(26)$ & $33.8(47)$ \\
\hline $1-2$ & $27.2(44)$ & $27.1(19)$ & $21.6(30)$ \\
\hline $3-4$ & $19.2(31)$ & $20.0(14)$ & $23.1(32)$ \\
\hline 5 or more & $18.4(30)$ & $15.8(11)$ & $21.5(30)$ \\
\hline \multicolumn{4}{|l|}{ Days with activity limitations in previous 2 weeks } \\
\hline 0 & $58.3(95)$ & $75.7(53)$ & $57.6(80)$ \\
\hline $1-2$ & $28.2(46)$ & $11.4(8)$ & $23.0(32)$ \\
\hline 3 or more & $13.5(22)$ & $12.9(9)$ & $19.4(25)$ \\
\hline \multicolumn{4}{|l|}{ School absences in previous 2 weeks } \\
\hline 0 & $63.0(102)$ & $67.1(47)$ & $51.4(71)$ \\
\hline $1-2$ & $25.3(41)$ & $15.7(11)$ & $27.5(38)$ \\
\hline 3 or more & $11.7(19)$ & $17.2(12)$ & $21.1(29)$ \\
\hline \multirow{2}{*}{ Symptom severity [mean \pm SD] } & $4.8 \pm 3.0$ & $4.6 \pm 3.3$ & $4.9 \pm 3.0$ \\
\hline & \multicolumn{3}{|c|}{ Urgent health care utilization (\% $[n])$} \\
\hline \multicolumn{4}{|l|}{ Acute medical visits in previous 2 months } \\
\hline 0 & $52.4(86)$ & $58.6(41)$ & $50.0(69)$ \\
\hline 1 & $25.6(42)$ & $17.1(12)$ & $21.7(30)$ \\
\hline 2 or more & $22.0(36)$ & $24.3(17)$ & $28.3(39)$ \\
\hline \multicolumn{4}{|l|}{ ED visits in previous 2 months } \\
\hline 0 & $74.4(122)$ & $85.6(59)$ & $76.3(106)$ \\
\hline 1 & $13.4(22)$ & $7.2(5)$ & $8.6(12)$ \\
\hline \multirow[t]{2}{*}{2 or more } & $12.2(20)$ & $7.2(5)$ & $15.4(21)$ \\
\hline & \multicolumn{3}{|c|}{ Asthma management (mean $\pm S D$ ) } \\
\hline Asthma Prevention Index & $11.01 \pm 4.1$ & $11.29 \pm 5.01$ & $11.16 \pm 4.3$ \\
\hline Asthma Management Index & $5.79 \pm 1.3$ & $5.92 \pm 1.2$ & $6.01 \pm 1.0$ \\
\hline Takes a long-term control medication ( $\%[n]$ yes) & $64.6 \pm 106$ & $75.7 \pm 53$ & $67.6 \pm 94$ \\
\hline
\end{tabular}

Normal, normal weight, $\mathrm{BMI}<85$ th percentile.

OW, overweight, 85 th $\leq$ BMI $<95$ th percentile.

$\mathrm{OB}$, obese, $\mathrm{BMI} \geq 95$ th percentile.

utilization of health care services for asthma, or worse asthma management by their children.

These results are consistent with some previous studies ${ }^{29-}$ 31,45 that have failed to show an association between weight status and markers of asthma morbidity. For instance, in a multi-center prospective cohort study of 672 patients seen in the ED for asthma, Ginde et al. found that obese children did not have worse asthma severity, increased steroid use, or more hospitalizations compared with non-obese children. ${ }^{31}$ However, unlike our study, other studies suggest that obese children with asthma have worse asthma morbidity and greater health care utilization, including being more likely to be prescribed 3 or more asthma medications and to have more days with wheezing, more ED visits, and more hospitalizations. ${ }^{24-28,46}$ Recently, in a cross-sectional study examining the electronic medical records of adolescents enrolled in an integrated health plan where approximately 74,000 children had current asthma, Black et al. found that extremely obese youth had higher rates of asthma-related ambulatory care visits and ED visits compared with normal weight youth. ${ }^{46}$

One reason that obesity may have been associated with worse asthma morbidity and greater health care utilization in some studies, but not others (including ours), may have to do with the variability of asthma control and morbidity. In our study, all children needed to have signs and symptoms of uncontrolled asthma to be eligible for the larger controlled trial from which these data were drawn. Similarly, Ginde et al. failed to show a difference in asthma morbidity based on weight status in 1,184 predominately ethnic minority children from 17 U.S. states and 2 Canadian provinces. ${ }^{31}$ This may also have been due to limited variability in asthma control, as all the children were recruited from the ED and had relatively high levels of uncontrolled asthma. In contrast, other studies showing a relationship between obesity and asthma morbidity appear to have more variability in asthma severity. ${ }^{24,26-28}$ Further studies are needed to test this potential association.

Relative to normal weight and obese youth, overweight youth had higher odds of having no days with activity limitations due to asthma (ie, being in the sure zero population); however, among those with activity limitations, overweight youth had more days with activity limitations than normal weight youth on an average. In addition, we found that that overweight, but not obese, youth had more school absences than normal weight youth. These findings 
are somewhat surprising; if weight is associated with more absences and limitations, we would have expected to find an even greater impact in the obese children when compared with normal weight and overweight youth, especially given that most were very obese (ie, BMI of 97th percentile or greater).Thus, these findings should be interpreted with caution. We suspect that there may be unmeasured confounding variables (eg, prednisone use, anxiety issues) affecting both BMI percentile and asthma morbidity that may account for this. Future studies should elucidate this further.

Despite the lack of a strong association between obesity and asthma morbidity, health care utlization, and asthma management in our sample, we found a high prevalence of overweight and obesity in this urban sample, with rates much higher than the national estimates; this relationship was stronger among Hispanics than Blacks, a result consistent with the recent study by Black et al. ${ }^{46}$ While the relationship between obesity and asthma is well known, ${ }^{22}$ of interest is our finding that the obese children in our sample tended to have BMI percentiles greater than 97, indicating more severe obesity. In fact, there were more very obese children in our study than obese and overweight children combined. This is clinically significant, because obesity places children at a high risk of diabetes, ${ }^{47}$ cardiovascular disease, ${ }^{47}$ and impaired lung functioning, ${ }^{48}$ and negatively impacts their quality of life and longterm survival. ${ }^{49,50}$ Moreover, when asthma is left untreated, it can lead to irreversible airway obstruction. ${ }^{51}$ Thus, whether or not obesity ultimately is found to directly worsen asthma, given the comorbidity of these 2 diseases, there is an urgent need for health care providers to address both issues concurrently to reduce long-term morbidity.

Several mechanisms have been proposed that may explain the high prevalence of severe obesity in our sample of early adolescents with uncontrolled asthma. For instance, asthma may cause increased psychological stress on the child and the family. ${ }^{52,53}$ Psychological stress ${ }^{54}$ and stress hormones $^{55}$ have been associated with childhood obesity. Asthma may also be a financial stressor, leading to greater food insecurity, another potential contributor to obesity. ${ }^{56}$ Pro-inflammatory cytokines seen in asthma may also worsen obesity. ${ }^{55}$ Asthma medications, especially oral steroids, may cause weight gain. ${ }^{57}$ Finally, patients with both obesity and asthma are more likely to be sedentary, ${ }^{58}$ which may exacerbate both conditions. Future research needs to further elucidate the causal mechanism in this population.

Regardless of the cause, the high prevalence of obesity among youth with asthma is an urgent health issue. Since weight reduction has been found to improve asthma severity and symptoms, ${ }^{22,23}$ more resources and programs are necessary to help promote weight reduction and healthy lifestyle habits, such as exercise and improved nutrition, among those who are overweigth or obese. In addition, obesity programs that target normal weight children with asthma are needed, as these children are at such high risk for obesity. These prevention and intervention programs should also teach asthma managmenet practices to improve asthma control and outcomes. ${ }^{38,59}$ Our finding that there were no differences in asthma management practices by weight category suggest that this education does not need to be tailored specifically for overweight and obese children. 
We also found it concerning that asthma was undertreated in our sample, with $32 \%$ of the parents reporting that their child was not using long-term control medications, despite the majority having persistent asthma. This is consistent with other studies that show the underuse of such medications. ${ }^{59,60}$ Moreover, use of long-term control medication was not associated with weight status in this at-risk sample, supporting that undertreatment of asthma is not an obesity-specific problem.

There are some limitations to our study. The crosssectional design can only measure associations rather than causation, and the sample size precluded us from conducting subgroup analyses that may have better clarified the relationship between obesity and asthma morbidity. In addition, this was a secondary data analyisis, and our study was not specifically designed to measure the impact of obesity on asthma outcomes. Thus, we can only make limited conclusions. The strengths of our study included that we looked at an underserved population, namely low-income, Hispanic, and Black early adolescents with uncontrolled asthma, and that we considered the relationship between obesity and asthma management as something not previously examined to this study.

In conclusion, in an underserved, largely Hispanic, and Black population of urban middle-school students with uncontrolled asthma, weight status was not associated with several measures of asthma morbidity, urgent health care utilization, and asthma management. Despite this, this study is important, because it specifically explores asthma prevention and management behaviors as they relate to obesity, and because it further highlights the co-morbidity of asthma and obesity, as well as the under-treatment of asthma in urban youth.

\section{Acknowledgments}

This research was supported by the National Heart, Lung, and Blood Institute at the National Institutes of Health (R01HL079953; PI= J.-M.B.).

\section{Authorship Credit}

M.J. (1) contributed to the interpretation of analyses; (2) took the lead on writing and revising the manuscript; and (2) provided final approval of the submitted version. N.A.W. (1) contributed substantially to the analyses and interpretation of analyses; (2) drafted parts of the methods section, the full results section, and tables, and revised the manuscript; and (3) provided final approval of the submitted version. C.S. (1) supervised the data acquisition, contributed to the analyses and interpretation of analyses; (2) assisted in writing and revising the manuscript, including drafting part of the methods and discussion sections; and (3) provided final approval of the submitted version. K.D. (1) helped conceptualize the article and contributed to the interpretation of analyses; (2) revised the manuscript for important intellectual content; and (3) provided final approval of the submitted version. D.M.C. (1) assisted with the data acquisition, and contributed to the interpretation of analyses; (2) assisted in writing and revising the manuscript by conducting literature searches, drafting parts of the introduction and discussion sections, and assisting with preparing the tables; and (3) provided final approval of the submitted version. J.-M.B.
(1) conceptualized and designed the study, including developing data acquisition methods, and contributed to the analyses and interpretation of analyses; (2) contributed to writing and revising the manuscript for important intellectual content; and (3) provided final approval of the submitted version.

\section{Author Disclosure Statements}

M.J. has no actual or potential conflicts of interest, either personal or financial.

N.A.W. has no actual or potential conflicts of interest, either personal or financial.

C.S. has no actual or potential conflicts of interest, either personal or financial.

K.D. has no actual or potential conflicts of interest, either personal or financial.

D.M.C. has no actual or potential conflicts of interest, either personal or financial.

J.-M.B. has no actual or potential conflicts of interest, either personal or financial.

\section{References}

1. Ogden CL, Carroll MD, Curtin LR, McDowell MA, Tabak CJ, Flegal KM. Prevalence of overweight and obesity in the United States, 1999-2004. JAMA 2006; 295:1549-1555.

2. Akinbami LJ, Moorman JE, Garbe PL, Sondik EJ. Status of childhood asthma in the United States, 1980-2007. Pediatrics 2009; 123 Suppl 3:S131-S145.

3. Bloom B, Cohen RA, Freeman G. Summary health statistics for U.S. children: National Health Interview Survey, 2007. Vital Health Stat 2009; 10:1-80.

4. ISAAC. Worldwide variations in the prevalence of asthma symptoms: The International Study of Asthma and Allergies in Childhood (ISAAC). Eur Respir J 1998; 12:315-335.

5. CDC. Self-reported asthma among high school students-United States, 2003. MMWR Morb Mortal Wkly Rep 2005; 54: 765-767.

6. Akinbami LJ, Schoendorf KC. Trends in childhood asthma: prevalence, health care utilization, and mortality. Pediatrics 2002; 110:315-322.

7. Claudio L, Stingone JA, Godbold J, Claudio L, Stingone JA, Godbold J. Prevalence of childhood asthma in urban communities: the impact of ethnicity and income. Ann Epidemiol 2006; 16:332-340.

8. Aligne CA, Auinger P, Byrd RS, Weitzman M. Risk factors for pediatric asthma: contributions of poverty, race, and urban residence. Am J Respir Crit Care Med 2000; 162:873-877.

9. Ogden CL, Flegal KM, Carroll MD, Johnson CL. Prevalence and trends in overweight among U.S. children and adolescents, 1999-2000. JAMA 2002; 288:1728-1732.

10. Ogden CL, Carroll MD, Curtin LR, Lamb MM, Flegal KM. Prevalence of high body mass index in US children and adolescents, 2007-2008. JAMA 2010; 303:242-249.

11. Davis AM, Bennett KJ, Befort C, Nollen N. Obesity and related health behaviors among urban and rural children in the United States: data from the National Health and Nutrition Examination Survey 2003-2004 and 2005-2006. J Pediatr Psychol 2011; 36: 669-676.

12. Wang Y, Liang H, Tussing L, Braunschweig C, Caballero B, Flay B. Obesity and related risk factors among low socio-economic status minority students in Chicago. Public Health Nutr 2007; 10:927-938.

13. Wang Y, Tussing L, Odoms-Young A, Braunschweig C, Flay B, Hedeker D, et al. Obesity prevention in low socioeconomic status urban African-american adolescents: study design and 
preliminary findings of the HEALTH-KIDS Study. Eur J Clin Nutr 2006; 60:92-103.

14. Baskin ML, Ard J, Franklin F, Allison DB. Prevalence of obesity in the United States. Obes Rev 2005; 6:5-7.

15. Matricardi PM, Gruber C, Wahn U, Lau S, Matricardi PM, Gruber C, et al. The asthma-obesity link in childhood: open questions, complex evidence, a few answers only. Clin Exp Allergy 2007; 37:476-484.

16. Daniels J. Weight and weight concerns: are they associated with reported depressive symptoms in adolescents? J Pediatr Health Care 2005; 19:33-41.

17. Akerman A, Williams ME, Meunier J. Perception versus reality: an exploration of children's measured body mass in relation to caregivers' estimates. J Health Psychol 2007; 12:871-882.

18. Chen Y, Dales R, Krewski D, Breithaupt K. Increased effects of smoking and obesity on asthma among female Canadians: the National Population Health Survey, 1994-1995. Am J Epidemiol 1999; 150:255-262.

19. Hancox RJ, Milne BJ, Poulton R, Taylor DR, Greene JM, McLachlan CR, et al. Sex differences in the relation between body mass index and asthma and atopy in a birth cohort. Am J Respir Crit Care Med 2005; 171:440-445.

20. Saha C, Riner ME, Liu G, Saha C, Riner ME, Liu G. Individual and neighborhood-level factors in predicting asthma. Arch Pediatr Adolesc Med 2005; 159:759-763.

21. Story RE. Asthma and obesity in children. Curr Opin Pediatr 2007; 19:680-684.

22. Ford ES. The epidemiology of obesity and asthma. J Allergy Clin Immunol 2005; 115:897-909.

23. Sin DD, Sutherland ER. Obesity and the lung: 4. obesity and asthma. Thorax 2008; 63:1018-1023.

24. Luder E, Melnik TA, DiMaio M. Association of being overweight with greater asthma symptoms in inner city Black and Hispanic children. J Pediatr 1998; 132:699-703.

25. Belamarich PF, Luder E, Kattan M, Mitchell H, Islam S, Lynn $\mathrm{H}$, et al. Do obese inner-city children with asthma have more symptoms than nonobese children with asthma? Pediatrics 2000; 106:1436-1441.

26. Herrera-Trujillo M, Barraza-Villarreal A, Lazcano-Ponce E, Hernandez B, Sanin LH, Romieu I. Current wheezing, puberty, and obesity among mexican adolescent females and young women. J Asthma 2005; 42:705-709.

27. Carroll CL, Bhandari A, Zucker AR, Schramm CM. Childhood obesity increases duration of therapy during severe asthma exacerbations. Pediatr Crit Care Med 2006; 7:527-531.

28. Abramson NW, Wamboldt FS, Mansell AL, Carter R, Federico MJ, Wamboldt MZ. Frequency and correlates of overweight status in adolescent asthma. J Asthma 2008; 45:135-139.

29. Hom J, Morley EJ, Sasso P, Sinert R. Body mass index and pediatric asthma outcomes. Pediatr Emerg Care 2009; 25:569-571.

30. Gennuso J, Epstein LH, Paluch RA, Cerny F. The relationship between asthma and obesity in urban minority children and adolescents. Arch Pediatr Adolesc Med 1998; 152:1197-1200.

31. Ginde AA, Santillan AA, Clark S, Camargo CA, Jr. Body mass index and acute asthma severity among children presenting to the emergency department. Pediatr Allergy Immunol 2010; 21:480-488.

32. Shore SA, Fredberg JJ. Obesity, smooth muscle, and airway hyperresponsiveness. J Allergy Clin Immunol 2005; 115:925-927.

33. King GG, Brown NJ, Diba C, Thorpe CW, Muñoz P, Marks GB, et al. The effects of body weight on airway calibre. Eur Respir J 2005; 25:896-901.

34. Rubinstein I, Zamel N, Dubarry L, Hoffstein V. Airflow limitation in morbidly obese, nonsmoking men. Anesthesiology 1990; 34:352.

35. Gump A, Haughney L, Fredberg J. Relaxation of activated airway smooth muscle: relative potency of isoproterenol vs. tidal stretch. J Appl Physiol 2001; 90:2306-2310.
36. Bruzzese J-M, Unikel LH, Gallagher R, Evans D, Colland VT. Feasibility and impact of a school-based intervention for families of urban adolescents with asthma: results from a randomized pilot trial. Fam Process 2008; 47:95-113.

37. N.H.L.B.I. Guidelines for the diagnosis and management of asthma NIH publication No. 97-4051. Bethesda: NIH, 1997.

38. N.H.L.B.I. Expert panel report 3: guidelines for the diagnosis and management of asthma. NIH Publication No. 07-4051. Bethesda: NIH, 2007, p. i-417.

39. Division of Nutrition Physical Activity and Obesity. A SAS program for the CDC growth charts. National Center for Chronic Disease Prevention and Health Promotion, 2009.

40. Wahlgren DR, Hovell MF, Matt GE, Meltzer SB, Zakarian JM, Meltzer EO. Toward a simplified measure of asthma severity for applied research. J Asthma 1997; 34:291-303.

41. Bruzzese J-M, Mellins RB, Evans D. Asthma self-management indices: manual and instructions for the asthma: it's a family affair study. NYU School of Medicine, 2010.

42. Ogden CL, Carroll MD, Flegal KM. High body mass index for age among US children and adolescents, 2003-2006. JAMA 2008; 299:2401-2405.

43. Lambert D. Zero-inflated Poisson regression, with an application to defects in manufacturing. Technometrics 1992; 34: $1-14$.

44. Dietz E, Böhning D. On estimation of the Poisson parameter in zero-modified Poisson models. Comput Stat Data Anal 2000; 34:441-459.

45. Kattan M, Kumar R, Bloomberg GR, Mitchell HE, Calatroni A, Gergen PJ, et al. Asthma control, adiposity, and adipokines among inner-city adolescents. J Allergy Clin Immunol 2010; 125:584-592.

46. Black M, Smith N, Porter A, Jacobsen S, Koebnick C. Higher prevalence of obesity among children with asthma. Obesity (Silver Spring) 2012; 20:1041-1047.

47. Weiss R, Dziura J, Burgert TS, Tamborlane WV, Taksali SE, Yeckel CW, et al. Obesity and the metabolic syndrome in children and adolescents. N Engl J Med 2004; 350:2362-2374.

48. Chu YT, Chen WY, Wang TN, Tseng HI, Wu JR, Ko YC. Extreme BMI predicts higher asthma prevalence and is associated with lung function impairment in school-aged children. Pediatr Pulmonol 2009; 44:472-479.

49. Bjorge T, Engeland A, Tverdal A, Smith GD. Body mass index in adolescence in relation to cause-specific mortality: a follow-up of 230,000 Norwegian adolescents. Am J Epidemiol 2008; 168: 30-37.

50. Reilly JJ, Kelly J. Long-term impact of overweight and obesity in childhood and adolescence on morbidity and premature mortality in adulthood: systematic review. Int J Obes 2011; 35: 891-898.

51. Vonk JM, Jongepier H, Panhuysen CIM, Schouten JP, Bleecker ER, Postma DS. Risk factors associated with the presence of irreversible airflow limitation and reduced transfer coefficient in patients with asthma after 26 years of follow up. Thorax 2003; 58:322-327.

52. Gillaspy SR, Hoff AL, Mullins LL, Van Pelt JC, Chaney JM. Psychological distress in high-risk youth with asthma. J Pediatr Psychol 2002; 27:363-371.

53. Bruzzese JM, Unikel LH, Shrout PE, Klein RG. Youth and parent versions of the asthma-related anxiety scale: development and initital testing. Pediatr Allergy Immunol Pulmonol 2011; 24: 95-105.

54. Koch F-S, Sepa A, Ludvigsson J. Psychological stress and obesity. J Pediatr 2008; 153:839-844.

55. Kyrou I, Chrousos GP, Tsigos C. Stress, visceral obesity, and metabolic complications. Ann N Y Acad Sci 2006; 1083: 77-110.

56. Barnes PJ. The cytokine network in asthma and chronic obstructive pulmonary disease. J Clin Invest 2008; 118:3546-3556. 
57. Akerman MJH, Calacanis CM, Madsen MK. Relationship between asthma severity and obesity. J Asthma 2004; 41:521-526.

58. Romieu I, Mannino DM, Redd SC, McGeehin MA. Dietary intake, physical activity, body mass index, and childhood asthma in the Third National Health And Nutrition Survey (NHANES III). Pediatr Pulmonol 2004; 38:31-42.

59. Bruzzese J-M, Stepney C, Fiorino EK, Bornstein L, Wang J, Petkova $\mathrm{E}$, et al. Asthma self-management is sub-optimal in urban Hispanic and African American/black early adolescents with uncontrolled persistent asthma. J Asthma 2012; 49:90-97.

60. Gustafsson PM, Watson L, Davis KJ, Rabe KF. Poor asthma control in children: evidence from epidemiological surveys and implications for clinical practice. Int J Clin Pract 2006; 60:321-334.
Address correspondence to: Jean-Marie Bruzzese, Ph.D.

Department of Child and Adolescent Psychiatry New York University School of Medicine 215 Lexingon Avenue, 13th floor New York, NY 10016

E-mail: jean-marie.bruzzese@nyumc.org

Received for publication January 30, 2012; accepted after revision June 10, 2012. 